\title{
COMPARISON OF PROGRESSIVE MUSCULAR RELAXATION (PMR) AND MUSIC THERAPY (MT) IN REDUCING THE ANXIETY, DEPRESSION AND STRESS SYMPTOMS AMONG NURSES
}

\author{
Nazia Mustafa, Midhat Farzeen*, Shoaib Kiani, Sana Khan**, Noor Ul Ain***, Jaweria Mumtaz ${ }^{* * * *}$ \\ General Headquarter, Rawalpindi Pakistan, *Ministry of National Health Services, Islamabad Pakistan, **Pakistan Naval Ship, Shifa Hospital, Karachi Pakistan, \\ ***Pakistan Naval Ship Shifa Hospital, Karachi Pakistan, ${ }^{* * * *}$ Tehsil Headquarter Hospital, Arif Wala, Pakpattan, Pakistan
}

\begin{abstract}
Objective: To compare the progressive muscular relaxation and music therapy in reducing the anxiety, depression and stress symptoms among nurses.

Study Design: Quasi-experimental study.

Place and Duration of Study: Various hospitals in Rawalpindi, from Mar 2018 to Mar 2019.

Methodology: Sample of study was 20 female nurses. They were assessed by using depression, anxiety and stress scale (DASS21), Urdu version. Study participants were randomized into two groups, group 1=who received the music therapy ( $\mathrm{n}=10$ ); group $2=$ who receive progressive muscular relaxation $(n=10)$. Both the groups were provided with 4 sessions of both interventions for one month. After completion of intervention, post assessment was carried immediately and analysis was carried out. Results: Mean age of nurses was $31 \pm 7.42$ years (range from 19-45 years). Significant difference was found which showed that progressive muscular relaxation was more effective in reducing the symptoms of depression and stress as compared to music therapy. Whereas, no significant difference $(p>0.05)$ was found on anxiety (both the treatments equally reduced the anxiety). Conclusion: Progressive muscular relaxation was found to be more effective in reducing stress and depression in nurses than music therapy. The use of such techniques can serve as an additional therapy in the treatment of stress, anxiety and depression and can be used to reduce the need for pharmacological therapy.
\end{abstract}

Keywords: Anxiety, Depression, Music therapy (MT), Progressive Muscular Relaxation (PMR), Stress.

How to Cite This Article: Mustafa N, Farzeen M, Kiani S, Khan S, Ain NU, Mumtaz J. Comparison of Progressive Muscular Relaxation (PMR) And Music Therapy (MT) in Reducing the Anxiety, Depression and Stress Symptoms Among Nurses. Pak Armed Forces Med J 2021; 71(6): 1930-1932. Doi; https://doi.org/10.51253/pafmj.v6i6.6338

This is an Open Access article distributed under the terms of the Creative Commons Attribution License (https://creativecommons.org/licenses/by-nc/4.0/), which permits unrestricted use, distribution, and reproduction in any medium, provided the original work is properly cited.

\section{INTRODUCTION}

Stress is a multidimensional phenomenon that is expressed by interaction of individual with their environment and can result in various issues e.g. mental health issues, physical illnesses, sleep disturbances, restlessness and irritability, forgetfulness and cognitive impairments. ${ }^{1}$ Nurses are at the higher risk due to extremely challenging nature of work. Mostly their stress is related to critical environment of the hospital $(77.13 \%)$, patient's mortality $(75.7 \%)$ and transmission of contagious diseases. ${ }^{2}$ This stress effects mental and physical health of nurses by causing adjustment issues and ultimately leads to poor quality of life. ${ }^{3,4}$ According Assadi et al. psychological problems were more prevalent among women medical students and nurses. ${ }^{5}$ Therefore, it is important to focus on these aspects by providing and teaching nurses with psychological management of stress.

There are many effective treatments including anti-depressant medications, cognitive-behavioral

Correspondence: Dr Nazia Mustafa, Clinical Psychologist, PA Dte, General Headquarter, Rawalpindi Pakistan

Received: 20 Feb 2021; revision received: 03 Sep 2021; accepted: 07 Sep 2021 psychotherapies, relaxation and unstructured therapy techniques. ${ }^{6}$ Relaxation techniques have been central in the area of stress and preventive measures. ${ }^{7}$ Progressive muscular relaxation (PMR), developed by Jacobson in 1934, is based on the notion that anxiety-provoking thoughts and events produce physiological tension. The technique involves progressively tensing and relaxing muscles in different parts of the body, leading to a reduction in physiological tension. ${ }^{8}$ In 1973 Bernstein and Brokovec modified the technique to make it suitable to cognitive behavioral stress management ${ }^{9}$ by adding relaxation through recall, recall and counting and counting. Empirical evidence indicates that PMR reduces tension headaches, anxiety levels and insomnia, and aids in treating cancer and in chronic pain management.

Music is also play important role in the stress and anxiety. According to Standley, slow and quit music generally lowered the physiological responses to stress. Randomized controlled trials revealed the efficacy of a single progressive muscle relaxation session compared with a control condition on state anxiety, psychological stress, fatigue and subjective wellbeing in patients with schizophrenia. ${ }^{10}$ 
There are many researches carried out to compare the efficacy of various techniques in the treatment of these problems but there are very few such studies have been done in Pakistan. Therefore, the present study is any attempt to see the efficacy of two techniques (progressive muscular relaxation, and music therapy) in the management of anxiety, depression and stress. This study is very important in developing countries such as Pakistan with limited health care resources.

\section{METHODOLOGY}

Present research was a quasi-experimental study, designed to compare the progressive muscular relaxation and music therapy in reducing the anxiety, depression and stress symptoms among the nurses. Institutional Ethical Review Board permission was taken and confidentiality of the study participants was maintained.

Inclusion Criteria: Female nurses who were coming for consultation at various hospitals of Rawalpindi were included.

Exclusion Criteria: Those nurses who were diagnosed with any other psychiatric illness and were on drug treatment were excluded from the study.

Random sampling was used due to the limited number of available populations. There were approximately 8-10 nurses stationed at psychiatry wards of five hospitals. Therefore, using fish bowl method, four nurses were randomly recruited from each hospital to reach a sample of 20. Final sample included 20 female nurses who were coming for consultation at various hospitals from Rawalpindi in the year of 2018-2019.

The study purpose was explained to them and their consent had been taken. All the nurses were assessed by administering depression, anxiety and stress scale (DASS-21), Urdu version. DASS-21 is a set of three self-report scales designed to measure the emotional states of depression, anxiety and stress. ${ }^{11}$ On the completion of assessment, they were randomized in to two groups of treatment fgroup $1=$ who received the MT $(n=10)$; group $2=$ who receive PMR $(n=10)$. Both the groups were provided with 4 sessions of PMR and music therapy for one month. PMR was given to them by audio instruction in a male voice for muscle relaxation and music therapy was composed of CD containing slow music of few minutes. After completion of intervention, post assessment was carried immediately.

Data was analyzed by using Statistical Package for the social sciences (SPSS) version 24. Mean \pm SD was calculated for continuous variable. Frequency and percentage was calculated for categorical variables. Independent sample t-test at baseline and endpoint was used to compare the mean differences of two groups. The $p$-value of $\leq 0.05$ was considered significant.

\section{RESULTS}

Twenty female nurses was included in the study. Mean age of participants was $31 \pm 7.42$ years (range $19-45$ years). Fifteen $(75 \%)$ were married while $5(25 \%)$ were unmarried. Mean depression in music therapy group at base line was $14.00 \pm 2.26$ and in progressive muscular relaxation group was $12 \pm 2.57$. Mean anxiety in music therapy group was $13 \pm 1.52$ and in progressive muscular relaxation group was $12 \pm 3.1$. Mean stress of music therapy group was $19 \pm 1.85$ and progressive muscular relaxation group $18.50 \pm 1.78$. There was no significant difference between music therapy and progressive muscular relaxation on depression $p=0.114$, anxiety $p=0.339$ and stress $p=0.470$ at baseline shown in Table-I.

Table-I: Comparison of progressive muscular relaxation (PMR) group and music therapy group on depression, anxiety and stress at baseline.

\begin{tabular}{l|c|c|c}
\hline \multirow{2}{*}{ Scores } & \multicolumn{2}{|c|}{ Mean \pm SD } & \multirow{2}{p}{ - } \\
\cline { 2 - 3 } & $\begin{array}{c}\text { Music Therapy } \\
(\mathbf{n}=\mathbf{1 0})\end{array}$ & $\begin{array}{c}\text { Progressive Muscular } \\
\text { Relaxation }(\mathbf{n = 1 0 )}\end{array}$ & \\
\hline Depression & $14 \pm 2.26$ & $12 \pm 2.57$ & 0.114 \\
\hline Anxiety & $13 \pm 1.52$ & $12 \pm 3.19$ & 0.339 \\
\hline Stress & $19 \pm 1.85$ & $18.50 \pm 1.78$ & 0.470 \\
\hline
\end{tabular}

Mean depression of music therapy group after the completion of study, was $11.60 \pm 2.01$ and in progressive muscular relaxation group was $8 \pm 1.33$. Mean anxiety in the music therapy group after the completion of study, was $11.20 \pm 1.93$ and in progressive muscular relaxation was $10.20 \pm 3.60$. While mean stress of music therapy group after the completion of study was 16.20 \pm 3.15 and in progressive muscular relaxation group was $13.50 \pm 2.27$. There was significant difference between music therapy and progressive muscular relaxation on depression and stress $p<0.01$, anxiety at the end of the study, shown in Table-II.

Table II: Mean comparison of progressive muscular relaxation (PMR) group and music therapy group on depression, anxiety and stress at endpoint.

\begin{tabular}{l|c|c|c}
\hline \multirow{2}{*}{ Scores } & \multicolumn{2}{|c|}{ Mean \pm SD } & \multirow{p}{p}{ - } \\
\cline { 2 - 3 } & $\begin{array}{c}\text { Music Therapy } \\
(\mathbf{n}=\mathbf{1 0 )}\end{array}$ & $\begin{array}{c}\text { Progressive Muscular } \\
\text { Relaxation (n=10) }\end{array}$ & \\
\hline Depression & $11.60 \pm 2.01$ & $8 \pm 1.33$ & $<0.01$ \\
\hline Anxiety & $11.20 \pm 1.93$ & $10.20 \pm 3.60$ & 0.453 \\
\hline Stress & $16.20 \pm 3.15$ & $13.50 \pm 2.27$ & $<0.01$ \\
\hline
\end{tabular}




\section{DISCUSSION}

Stress is any intrinsic or extrinsic trigger that is capable of producing a biological response on the body and the response that is produced by the body in compensation is called stress response..$^{12}$ Consequently, stress produces various psychological effects in addition to the physiological effects and continued stress exposure is linked with poor psychological health. ${ }^{13}$

Various therapeutic techniques have been applied in the management of stress, anxiety and depression as the newly emerging field of behavioral medicine continues to progress. ${ }^{14} \mathrm{~A}$ study has recommended the use of music relaxation at night time to treat insomnia in patients of PTSD with no other psychiatric illness suggesting its effectiveness in improving the element of depression and sleep quality in these patients. ${ }^{15}$

Our study revealed that PMR was found to be more effective in reducing stress and depression in nurses than MT while there was no significant difference between the efficacies of the two therapeutic modalities on the anxiety of the nurses that formed a part of our sample population. This finding is in accordance with the study of Sheri et al, who found Music associated PMR, PMR, MT and silence to be equally effective in the producing significant changes in anxiety thus recommending them as effective relaxation techniques. ${ }^{16}$

A comparison of various relaxation techniques has been carried out on different sets of population throughout the world with PMR and MT both producing significant reduction in anxiety of the concerned population as proved by their pretest and posttest scores, e.g. the music performance anxiety of pianists had greater reduction with the usage of PMR and imagery techniques. ${ }^{17} \mathrm{~A}$ randomized controlled trail carried on nursing students revealed reduction of before exam stress and improvement in academic performance by the usage of a combination therapy comprising of MT and PMR. ${ }^{18}$ MT produced greater reduction in anxiety and dyspnea of patients of COPD as compared to PMR, a study revealed. ${ }^{19}$

The use of relaxation techniques like PMR and MT can serve as an additional therapy in the treatment of stress, anxiety and depression and can be used to reduce the need for pharmacological therapy in such patients and population of people. Our study produced reliable results regarding the effectiveness of PMR and MT in treating anxiety, stress and depression.

However due to a limited study sample, further research on the topic is recommended to enhance the evidence available thereby such treatment options are readily employed in the management of the patients in future.

\section{Conflict of Interest: None.}

\section{Authors' Contribution}

NM: Conceptualization of research, data collection and write-up, MF: Data collection, compilation and analysis, SK: Supervision over supervision and review of article, SK: data entry and data cleaning, NUA: Contribution in write-up, JM: Proof reading.

\section{REFERENCES}

1. Beddoe AE, Murphy SO. Does mindfulness decrease stress and foster empathy among nursing students? J Nurs Educ 2004; 43(7): 305-312.

2. Fathi M. Evaluation of stress factors and nurses in special sections of Kurdistan University of Medical Sciences in 2004. Sci J Kurd Univ Med Sci 2004; 7(4): 53-62.

3. Gammon J, Morgan-Samuel H. A study to ascertain the effect of structured student tutorial support on student stress, self-esteem and coping. Nurse Educ Pract 2005; 5(3): 161-171.

4. Ryan ME TR. Concerns, values, stress, coping, health and educational outcomes of college students who studied abroad. Int J Intercult Relat 2000; 24(2000): 409-435.

5. Assadi SM, Nakhaei MR, Najafi F, Fazel S. Mental health in three generations of Iranian medical students and doctors. A crosssectional study. Soc Psychiatr Epidemiol 2007; 42(1): 57-60.

6. Roy-Byrne P, Wingerson D, Cowley D, Dager S. Psychopharmacologic treatment of panic, generalized anxiety disorder, and social phobia. Psychiatr Clin North Am 1993; 16(4): 719-735.

7. Mandel SE. Music for wellness: Music therapy for stress management in a rehabilitation program. Music Ther Perspect 1996; 14(1): 38-43.

8. Davis M. Assertiveness: the relaxation and stress reduction workbook chapter singles. New Harbinger Publications; 2008.

9. Bernstein DA, Borkovec TD. Progressive relaxation training: a manual for the helping professions. Research Press, 2612 North Mattis Avenue, Champaign, Illinois; 1973.

10. Standley JM. Music research in medical/dental treatment: metaanalysis and clinical applications. J Music Ther 1986; 23(2): 56-122.

11. Aslam N. Translation, validation and effectiveness of depression, anxiety and stress scale (DASS-21) in assessing the psychological distress among flood affected individuals. J Pak Psych Soc 2021; 18: 16.

12. Yaribeygi H, Panahi $Y$, Sahraei H, Johnston TP. The impact of stress on body function: a review. Exc J 2017; 16(1): 1057-1072.

13. Zawadzki $M$, Sliwinski M. Perseverative cognitions and stress exposure: comparing relationships with psychological health across a diverse adult sample. Ann Behav Med 2018; 52(12): 1060-1072.

14. Kahn P, Fawcett J. The encyclopedia of mental health, 3rd edition. New York; 2007 [Internet] Available at: https://www. amazon.com/ Encyclopedia-Mental-Health-Library-Living/dp/0816064547

15. Blanaru M, Bloch B, Vadas L, Arnon Z, Ziv N, Kremer I, et al. The effects of music relaxation and muscle relaxation techniques on sleep quality and emotional measures among individuals with posttraumatic stress disorder. Ment Illn 2012; 4(2): e13-15.

16. Robb S. Music assisted progressive muscle relaxation, progressive muscle relaxation, music listening and silence: a comparison of relaxation techniques. J Music Ther 2000; 37(1): 2-21.

17. Kim Y. The effect of improvisation-assisted desensitization, and musicassisted progressive muscle relaxation and imagery on reducing pianists music performance anxiety. J Music Ther 2008; 45(2): 165-191.

18. Gallego-Gómez JI, Balanza S. Effectiveness of music therapy and progressive muscle relaxation in reducing stress before exams and improving academic performance in Nursing students: a randomized trial. Nurse Educ Today 2020; 84(1): 104217.

19. Singh VP, Rao V. Comparison of the effectiveness of music and progressive muscle relaxation for anxiety in COPD-A randomized controlled pilot study. Chronic Respir Dis 2009; 6(4): 209-216. 